\title{
Transcription of Sonic Hedgehog, a Potential Factor for Gastric Morphogenesis and Gastric Mucosa Maintenance, Is Up-regulated in Acidic Conditions
}

\author{
Arno Dimmler, Thomas Brabletz, Falk Hlubek, Manuela Häfner, Tilman Rau, \\ Thomas Kirchner, and Gerhard Faller
}

Institute of Pathology (AD, TB, FH, MH, TR, TK, GF), University of Erlangen-Nuremberg, Erlangen, Germany

\begin{abstract}
SUMMARY: Gastric body mucosa atrophy predisposes one to gastric cancer. Disturbances in the gastric differentiation process might play a role in the evolution of gastric atrophy. Sonic hedgehog (Shh) has recently been implicated as a crucial factor in gastric organogenesis and gland differentiation. In this study we investigated the expression of key factors in the Shh pathway, namely Shh and its receptor Patched (Ptc), in normal and pathologic stomach mucosa. Furthermore, the potential role of $\mathrm{pH}$ for Shh dysregulation was analyzed. Ten gastric biopsy specimens each from normal gastric mucosa, chronic nonatrophic gastritis, atrophic gastritis, and gastric cancer were included. Expression of Shh and Ptc was analyzed by immunohistochemistry. In normal body mucosa and in nonatrophic body gastritis, Shh was strongly expressed in parietal cells. Ptc was also expressed in gastric chief cells. Shh expression was almost completely lost in atrophic gastritis and in gastric cancer and absent in intestinal metaplasia. Ptc was markedly reduced in atrophy and only weakly positive in intestinal metaplasia and gastric cancer. In in vitro experiments, gastric cancer cell line 23132 was found positive for Shh. In long-term culture as well as in culture conditions with low $\mathrm{pH}$, transcription of Shh in 23132 was significantly increased in quantitative reverse transcription PCR analyses. We concluded that the decreased expression of the Shh pathway in atrophic gastritis and gastric cancer might reflect altered differentiation processes within the gastric unit and contributes to the development of gastric atrophy. The increase of gastric $\mathrm{pH}$ might play a role in the development of gastric mucosa atrophy via reduction of Shh transcription. (Lab Invest 2003, 83:1829-1837).
\end{abstract}

C hronic gastritis is one of the most prevalent chronic inflammatory diseases in humans. Corpus-predominant and atrophic gastritis represents an alteration with a significantly elevated risk for the development of gastric cancer (Uemura et al, 2001). However, the pathogenesis of gastric atrophy is not completely understood. Antigastric autoimmune reactions against gastric parietal cells are a well established process associated with a loss of gastric body glands in both autoimmune (type A) gastritis and in atrophic Helicobacter pylori gastritis (Claeys et al, 1998). Increased apoptosis, which can be initiated by autoreactive T-lymphocytes, has been implicated in the development of mucosal atrophy in these disorders (Steininger et al, 1998). However, recent longterm follow-up studies did not confirm an association of increased apoptosis and loss of gastric glands (Moss et al, 1999; Vorobjova et al, 2001). Thus, gastric

DOI: 10.1097/01.LAB.0000101729.25140.0C

Received September 18, 2003.

This work was supported by the Federal Ministry of Education and Research and the Interdisciplinary Center of Clinical Research at the University Hospital of Erlangen-Nuremberg.

Address reprint requests to: Dr. Gerhard Faller, Institute of Pathology, University of Erlangen-Nuremberg, Krankenhausstrasse 8-10, 91054 Erlangen, Germany. E-mail: Gerhard.Faller@patho.imed.uni-erlangen.de atrophy should primarily be regarded as a result of alterations in the differentiation process along the gastric pit-gland axis rather than of gland destruction.

Embryonal differentiation processes are regulated through a number of signal cascades. One of these cascades starts with the transcription factor Sonic hedgehog (Shh), which binds to its receptor Patched (Ptc). Dysregulations in this pathway have been shown to play a pivotal role in some inborn abnormalities like holoprosencephaly and polydactylia. Furthermore, the development of certain neoplastic diseases such as basalioma of the skin and glioblastoma are related to abnormalities in the Shh pathway (Mullor et al, 2002; Villavicencio et al, 2000).

In only a few studies, the role of Shh and related factors for gastric development has been analyzed. In the normal human stomach, Shh is expressed in gastric parietal cells, whereas its receptor Ptc is mainly present on gastric chief cells. Inhibition of the Shh pathway by cyclopamine leads to a reduced expression of gastric Shh target genes such as $H N F 3 \beta$, Isl-1, and BMP4 (van den Brink et al, 2001) and hyperproliferation of cells within the gastric unit. Furthermore, in the stomach of Shh knockout embryonic mice, no gastric but an intestinal differentiation is detectable (Ramalho-Santos et al, 2000). Hence it was speculated that Shh might play a role in gastric gland 
morphogenesis and maintenance (Silberg and Kaestner, 2001). To test this hypothesis further and to investigate the possible role of alterations in the Shh pathway for the development of gastric atrophy in humans, we analyzed the in situ expression pattern of key factors in this pathway, namely Shh and Ptc in the normal human gastric mucosa, in nonatrophic and atrophic gastritis, and in gastric cancer. Additionally, we analyzed the expression of CDX2, a relevant factor for intestinal differentiation and transdifferentiation processes (Silberg et al, 2002).

There is evidence that the loss of the acidic milieu in the stomach impairs gastric gland differentiation leading to gastric atrophy (Kakei et al, 1993, 1995; Kuipers et al, 1996; Lamberts et al, 2001). Moreover, chronic acid exposure of esophageal keratinocytes has very recently been shown to activate CDX2 (Marchetti et al, 2003). Thus, gastric acid might contribute to certain morphogenetic processes in the upper gastrointestinal tract. We therefore performed functional assays to analyze the potential role of $\mathrm{pH}$ for alterations in Shh transcription in a gastric cell culture system.

\section{Results}

\section{Immunohistochemistry}

Normal Adult Gastric Mucosa: In normal gastric corpus mucosa, Shh was strongly expressed in the cytoplasm of parietal cells in all cases (10/10). No gradual decrease of Shh expression along the pitgland axis could be seen (Fig. 1A). In all cases Ptc was expressed in parietal cells but also significantly in the cytoplasm of chief cells (Fig. 1D). Nuclear expression of CDX2 was absent in normal gastric mucosa (Fig. 1G). Apart from single and scattered parietal cells, Shh was only very weakly expressed in cells in the neck region of the normal antrum mucosa (Fig. 2A). Ptc was moderately expressed in cells in the neck region of the antrum (Fig. 2B).

Nonatrophic Body Gastritis: In all cases with nonatrophic body gastritis, the staining reactions were comparable to those found in normal gastric body mucosa: Shh was strongly expressed in parietal cell in nonatrophic body gastritis (16/16) (Fig. 1A). Addition-

\section{normal / nonatrophic gastritis}
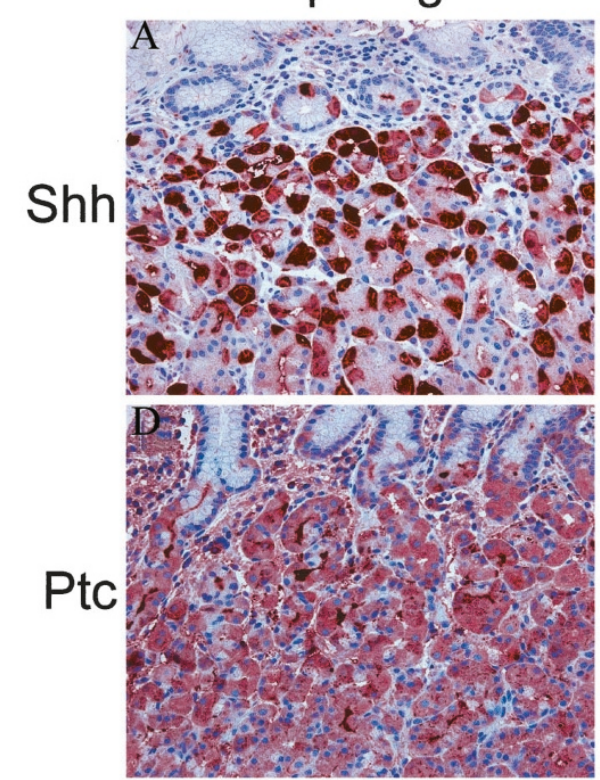

CDX2

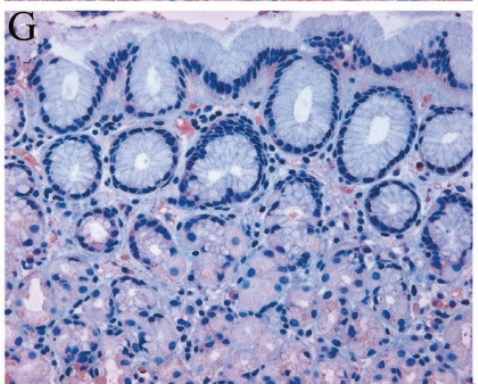

atrophic gastritis
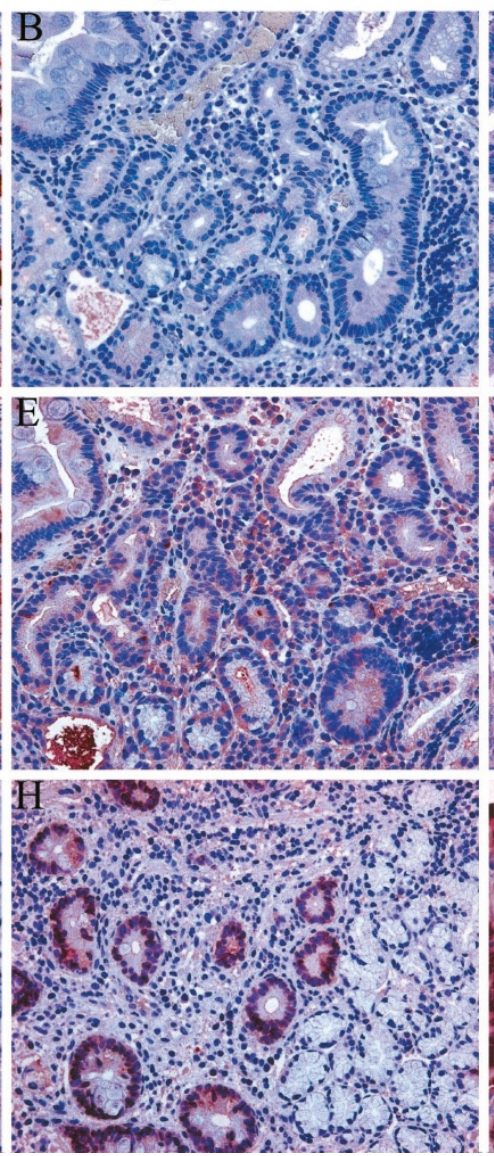

gastric cancer
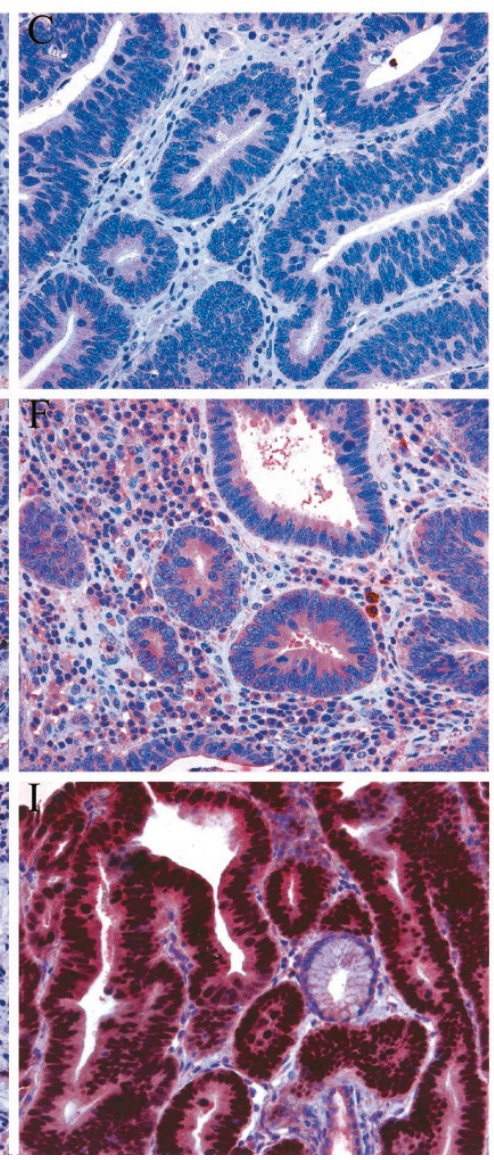

Figure 1.

Immunohistochemical detection of the expression of Sonic hedgehog (Shh) (A to C), Patched (Ptc) (D to F), and CDX2 (G to I) in normal gastric body mucosa and nonatrophic body gastritis (A, D, and $G$ ), in atrophic body gastritis with intestinal metaplasia (B, E, and $H)$, and in gastric adenocarcinoma of the intestinal subtype (C, F, and I). Shh is expressed in nonatrophic conditions in parietal cells (A), whereas Ptc is mainly detectable in gastric chief cells (D). In atrophy, metaplasia, and cancer, the expression of both factors is significantly reduced. Nuclear CDX2 expression is absent in normal gastric mucosa and in nonatrophic corpus gastritis (G) but is positive in intestinal metaplasia $(\mathrm{H})$ and in most cases with differentiated gastric cancer (I). (Immunostaining; original magnification, $\times 20$.) 


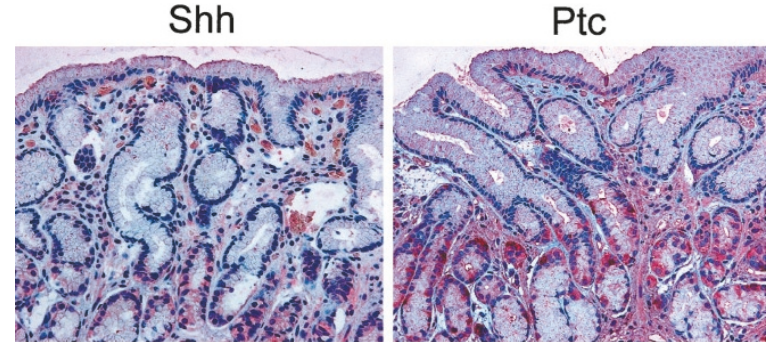

Figure 2.

Immunohistochemical detection of the expression of Sonic hedgehog (Shh) and patched (Ptc) in normal gastric antrum mucosa. (A) Shh is only very weakly detectable in flat cells in the neck region. (B) Ptc is moderately expressed in flat cells in the neck region often displaying a retronuclear staining pattern. (Immunostaining; original magnification, $\times 20$.)

ally, in 7 of 16 cases, Shh could also be detected basolaterally in the foveolar epithelium. Ptc was expressed mainly in chief cells and also in parietal cells (Fig. 1D). CDX2 was again absent in nonatrophic corpus gastritis (Fig. 1G).

Atrophic Gastritis: In all cases of atrophic body gastritis, Shh and Ptc were clearly expressed in mucosa areas where residual and differentiated gastric glands were still detectable. Atrophic areas with pseudopyloric or intestinal metaplasia were negative or only very weakly positive for Shh (Fig. 1B). Ptc was only weakly detectable in intestinal metaplasia and to a significantly lesser extent than in nonatrophic mucosa. (Fig. 1E). Nuclear CDX2 expression was found in all cases of intestinal metaplasia (10/10) (Fig. 1H).

Gastric Cancer: None of the investigated gastric carcinoma specimens showed positive staining for Shh (Fig. 1C). More than $80 \%$ of the samples (21/26) showed a weak and sometimes focally accentuated positivity of the tumor cells for Ptc (Fig. 1F). For this antigen, staining was evenly distributed without obvious relation to histoarchitecture of the carcinomas. Furthermore, there was no apparent correlation with histologic subtypes or grade of differentiation. Nuclear CDX2 expression was found in $65 \%(17 / 26)$ of the samples with gastric cancer. Proportion of CDX2 expression was higher in well- and moderately differentiated carcinomas $(12 / 15,80 \%)$ (Fig. 1I) than in poorly differentiated and undifferentiated cancer (5/ 11, 45\%).
Extragastric Intestinal Tissues: In the normal duodenum, Shh expression was not detectable in any tissue samples investigated (Fig. 3A). In five of five cases, Ptc was expressed only in very few epithelial cells scattered in the basal third of the mucosa. These cells showed a predominant retronuclear staining pattern (not shown). In the terminal ileum, Shh was negative in all cases (0/5) (Fig. 3B). Here, Ptc was negative or only very weakly detectable. In the proximal colon (coecum/colon ascendens) Shh and Ptc were negative or only very weakly visible in 8 of 8 cases (Fig. 3C). In the distal colon (sigma/rectum), Shh was strongly expressed in the luminal epithelial cells in six of seven cases. The epithelial cells in the crypts were only very weakly positive or negative for Shh (Fig. 3D). Ptc was negative or only very weakly positive in this compartment. Immunohistochemical investigations on Shh and Ptc expression in colon cancer revealed weak and sometimes focally accentuated cytoplasmic staining in the tumor cells. Staining was independent from tumor site or histologic grade (data not shown).

\section{Shh in Gastric Cancer Cell Lines}

Of the three gastric cancer cell lines 23132, HGT-1, and AGS only $23132 / 87$ cells synthesized detectable amounts of Shh. Shh expression was detected in immunocytochemistry (Fig. 4, A and B) and in Western blot (Fig. 4C). RNA coding for Shh was identified by reverse transcription (RT)-PCR and subsequent gel electrophoresis (Fig. 4D).

\section{Effect of Culture Conditions on Shh Transcription}

To investigate the possible effect of culture conditions on Shh transcription, 23132 cells were continuously cultured for 9 days under conditions described below. After 5 to 6 days in culture without changing the medium gastric cell line, 23132 cells reproducibly showed a significant (almost 10-fold) and persistent increase in Shh transcription as detected in quantitative RT-PCR experiments. This increase was not detectable if culture medium was changed every second day (Fig. 5). The number of cells in the experiments with or without changing the medium did not show significant differences (data not shown). Hence, factors in the medium rather than cell density have a duodenum

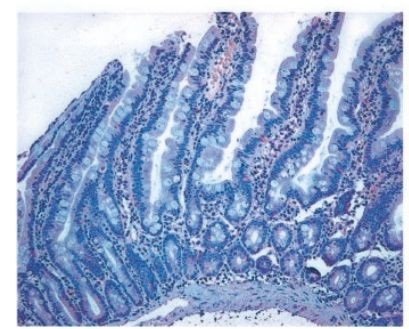

ileum

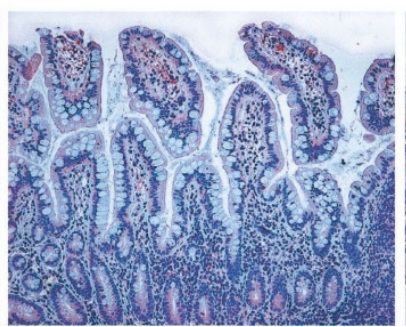

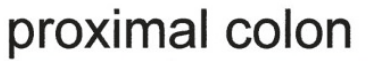

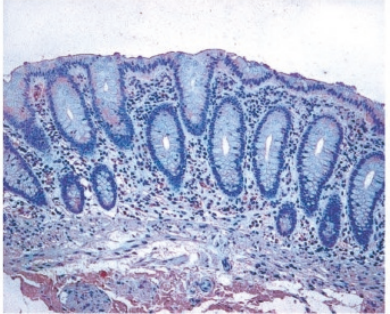

distal colon

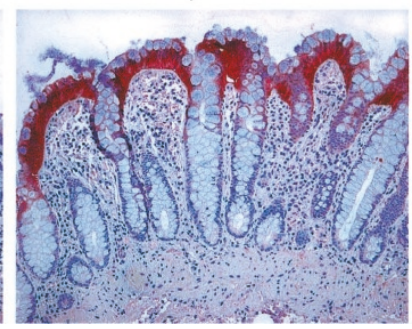

Figure 3.

Sonic hedgehog expression in the small bowel mucosa and in the colon. Sonic hedgehog is not expressed in the duodenum, ileum, and proximal colon, but is strongly detectable in the luminal layer of epithelial cells in the distal colon (sigma/rectum). (Immunostaining; original magnification, $\times 20$ ) 

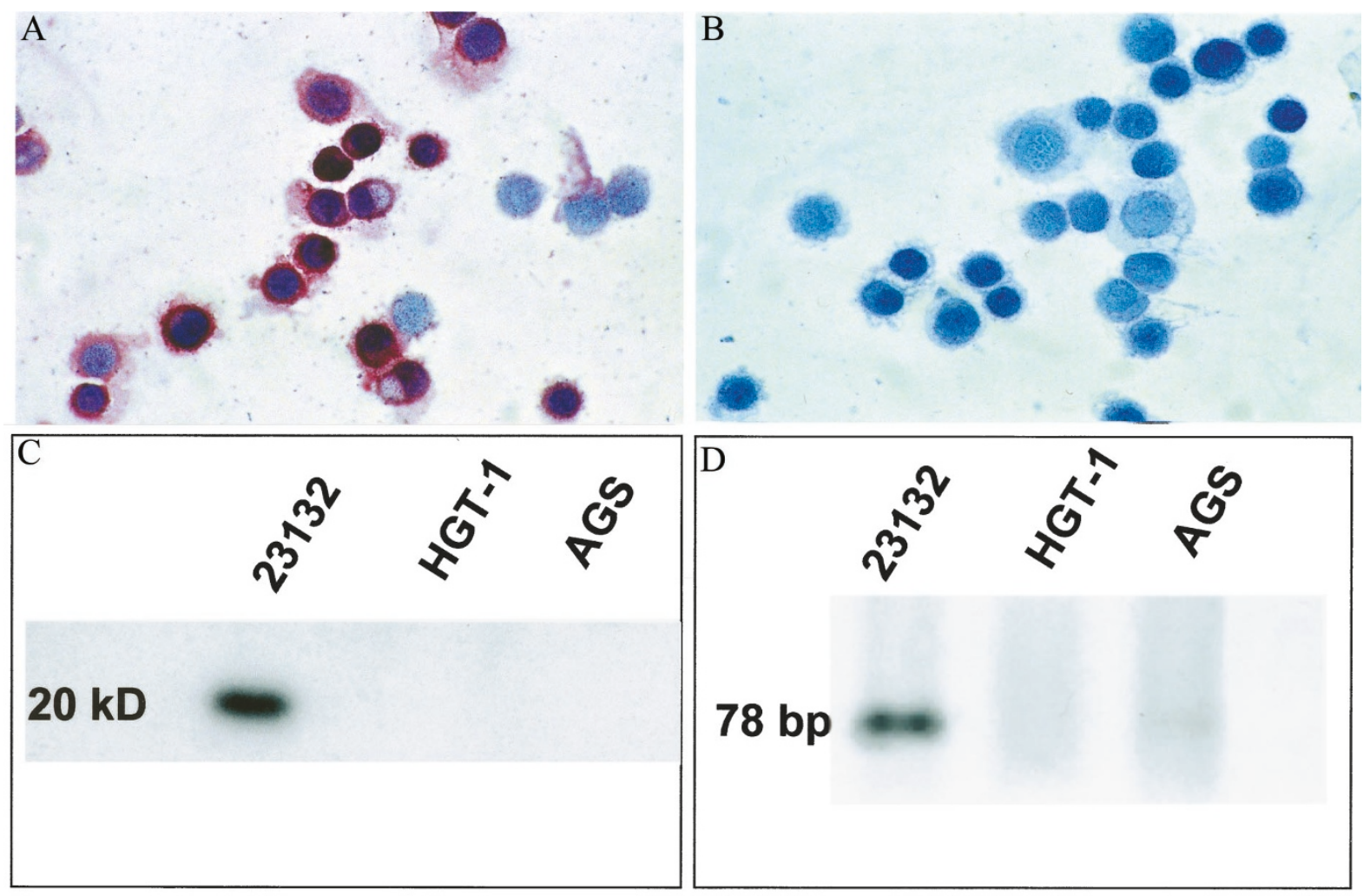

\section{Figure 4.}

(A) Detection of Sonic hedgehog (Shh) in human gastric cancer cell line 23132 by immunocytochemistry. (B) Omitting the Shh antibody as negative control did not result in staining 23132 cells. Detection of N-terminal fragment of Shh protein by Western blotting (C) and of Shh mRNA by reverse transcription PCR (D). Two other gastric cancer cell lines HGT-1 and AGS were negative for Shh in these assays.

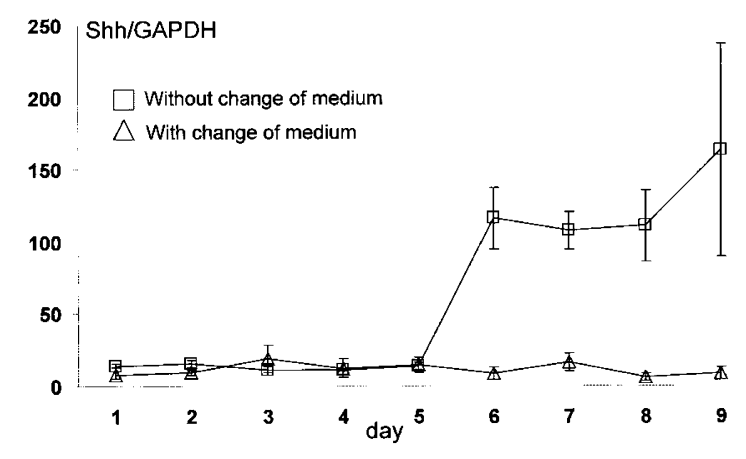

Figure 5.

Influence of cell culture conditions on Sonic hedgehog (Shh) transcription. Gastric cancer cell line 23132 showed a significant increase in Shh transcription in conditions without changing the medium (square). This increase was not detectable if culture medium was changed every second day (triangle). $G A P D H=$ glyceraldehyde-3-phosphate dehydrogenase.

substantial impact on Shh transcription. From the strong yellow color of unchanged culture medium, we concluded that $\mathrm{pH}$ value of the culture medium might influence Shh transcription.

\section{Effect of $\mathrm{pH}$ on Shh Transcription}

To analyze if $\mathrm{pH}$ value might be one of the factors responsible for the increase in Shh transcription in long-term culture conditions without change of medium, 23132 cells were placed in fresh culture media with different acid concentrations. In acidic $\mathrm{pH}$ (ie, $\mathrm{pH}$ 5.0), Shh expression of 23132 cells was highest, reaching $76.33 \pm 11.28$ molecules RNA per 1000 molecules GAPDH (glyceraldehyde-3-phosphate dehydrogenase). When increasing $\mathrm{pH}$ in culture medium, Shh expression gradually decreased to values of 8.66 \pm 2.21 at $\mathrm{pH} 7.5$. These results are shown in Figure 6 . The two other gastric cancer cell lines, HGT-1 and AGS, showed no significant induction of Shh transcription at acidic culture conditions (data not shown).

\section{Discussion}

In this study, we demonstrate that in normal adult gastric body mucosa and in nonatrophic body gastri-

\section{Shh/GAPDH}

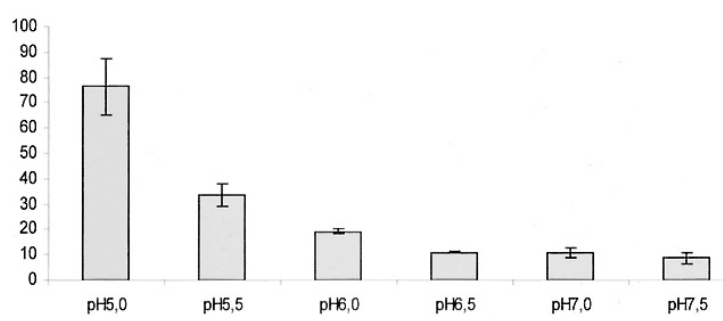

Figure 6.

Influence of $\mathrm{pH}$ in cell culture medium on Shh transcription as revealed by reverse transcription PCR. Shh transcription significantly increased with low pH. GAPDH = glyceraldehyde-3-phosphate dehydrogenase. 
tis, Shh is strongly expressed in parietal cells only. The Shh receptor Ptc is predominantly expressed on chief cells. However, the expression of both factors is significantly reduced in atrophic gastritis and in gastric adenocarcinoma. In the gastric cancer cell line 23132, which produces substantial amounts of Shh, low $\mathrm{pH}$ of cell culture medium significantly increases Shh transcription. Our data indicate that (a) Shh might represent a pivotal factor for the integrity of the gastric body mucosa, (b) the Shh pathway is severely dysregulated in gastric body mucosa atrophy with and without intestinal metaplasia, (c) the gastric parietal cell might act as central organizer of the gastric differentiation process via Shh expression, (d) low gastric $\mathrm{pH}$ might contribute to gastric gland morphogenesis via increased Shh transcription, and (e), vice versa, higher gastric $\mathrm{pH}$ might lead to failures in gastric differentiation processes and finally to the gastric atrophy.

Our results concerning Shh and Ptc expression in adult normal, nonatrophic, and atrophic gastric body mucosa and in the intestine are in good agreement with the findings of van den Brink et al (2001, 2002), who also investigated these factors by immunohistochemistry and in situ hybridization. However, in contrast to their description, we could not confirm a gradual decrease of Shh expression along the pitgland axis (van den Brink et al, 2001). Additionally, the expression of Shh in distal colon mucosa was not reported (van den Brink et al, 2002). The significance of this particular expression in the distal colon is unknown. Data from animal models indicate a potential role for Shh in hindgut development (Roberts et al, 1995). Furthermore, Mo et al (2001) recently showed that various defects in Shh signaling cause anorectal malformations like persistent cloaca and imperforate anus in mutant mice. However, the precise role of Shh expression in human adult distal colon remains to be elucidated, the more so as other factors in the Shh pathway are not present or only minimally present at this particular location. Also the possible role of Shh in the development of colon cancer needs to be further studied.

Our results concerning CDX2 expression in normal gastric mucosa, in chronic intestinal metaplasia, and in gastric cancer are in good agreement with earlier reports and confirm the essential role of CDX2 in the pathogenesis of intestinal metaplasia in chronic gastritis (Almeida et al, 2003; Seno et al, 2002; Silberg et al, 2002). Whether CDX2 up-regulation is the consequence of the decline in Shh and Ptc expression or results from hypoacidity needs to be further investigated.

The differential expression of Shh in parietal cells and the Shh receptor Ptc in chief cells indicates that a cross-talk between these two lines of differentiation might exist. Via Shh signaling, parietal cells could regulate the differentiation or maintenance of the gastric chief cells and of the whole gastric glandular compartment. Several types of gastric inflammatory conditions are associated with gastric mucosa atrophy, eg, classic autoimmune gastritis, chronic $H$. pylori gastritis with antigastric autoimmune reactions, and infection with $H$. pylori strains positive for the Cag pathogenicity island (Claeys et al, 1998; Eurohepygast, 2002). In all of these instances, cellular and humoral autoimmunity as well as bacterial virulence factors such as CagE, a substantial part of the Cagpathogenicity island, target gastric parietal cells (Neu et al, 2002). Hence, the reduction or the complete loss of the glandular unit in these conditions, where first and foremost the parietal cells are affected, could be explained (Judd et al, 1999). This concept is further confirmed by studies using transgenic mice that showed that genetic ablation of gastric parietal cells also leads to a block in the differentiation program of the chief cell lineage (Canfield et al, 1996; Li et al, 1996).

Our observation that Shh and Ptc are not expressed or only weakly expressed in gastric atrophy, intestinal metaplasia, and gastric cancer indicates that reduced expression of this pathway might be an early event in the proposed atrophy-metaplasia-carcinoma sequence (Correa, 1988) and that additional genetic and epigenetic factors are responsible for transformation of cells of gastric atrophy into gastric cancer cells. More clinical and experimental investigations are needed to further analyze these issues. However, the down-regulation of Shh in the gastric mucosa might be reversible. This could explain why in a subset of cases with atrophic gastritis, atrophy improves after adequate therapy (Tucci et al, 1998).

In an experimental model, treatment with the Shh pathway-inhibitor cyclopamine resulted in an increased proliferation within the gastric unit (van den Brink et al, 2001). Increased proliferation and cell turnover in this compartment were also described in patients with atrophy (Biasco et al, 1989; Miwa et al, 1997) and in animals treated with the proton pumpinhibitor omeprazole (Kakei et al, 1993, 1995). These animals, like the $\mathrm{H}, \mathrm{K}-\mathrm{ATP}$ ase knockout mice in previous studies (Scarff et al, 1999; Spicer et al, 2000), showed both achlorhydria and suppressed differentiation of gastric chief cells. Therefore, it might be speculated that gastric acid represents a key factor for gastric morphogenesis.

This concept is further substantiated by clinical trials applying omeprazole in which $10 \%$ of the $H$. pylori-negative and $40 \%$ of the $H$. pylori-positive patients developed gastric atrophic changes (Kuipers et al, 1996; Lamberts et al, 2001). Additionally, the results presented in our study showed a significant dependence of Shh transcription on acid exposure in a functional assay using a gastric cancer cell line. Further evidence for the potential role of acid on differentiation programs in the esophageal-gastrointestinal tract has recently been reported by Marchetti et al (2003), who showed that CDX2, a key factor for intestinal differentiation, is activated through acid exposure of esophageal keratinocytes. This $\mathrm{pH}$ triggered transdifferentiation might play a pivotal role in the generation of Barrett's mucosa in gastroesophageal reflux disease (Eda et al, 2003).

Gastric acid might only represent one factor leading to dysregulation in the expression of the Shh pathway 
in the gastric mucosa. It is well possible that other changes in the gastric milieu, eg, bacterial virulence factors of $H$. pylori, factors produced by the inflammatory infiltrate in chronic gastritis, and changes in the extracellular matrix composition in chronically inflamed gastric mucosa, also influence Shh transcription and expression. Therefore, more descriptive and experimental studies are needed to clarify the pathogenesis of Shh-dependent gastric mucosa alterations.

\section{Materials and Methods}

\section{Tissue Samples}

We analyzed gastric biopsy specimens with normal human adult gastric antrum $(n=10)$ and corpus $(n=$ 10) mucosa, with nonatrophic body gastritis $(n=16)$, and with atrophic body gastritis with intestinal metaplasia $(n=11)$. Furthermore, 26 paraffin-embedded archival tissue sections of gastric carcinoma (5 well, 10 moderately, 7 poorly differentiated and 4 undifferentiated, 22 of intestinal, and 4 of diffuse histologic subtype) were included in the study. Normal nongastric control tissues comprised biopsy specimens of the duodenum $(n=5)$, ileum $(n=5)$, proximal $(n=8)$, and distal colon $(n=7)$, respectively. Additionally we analyzed 20 specimens with colon cancer. Ten specimens were from proximal colon cancer (cecum/colon ascendens) and 10 from the rectum.

\section{Immunohistochemistry and Immunocytochemistry}

All tissue specimens were fixed in 10\% formaldehyde and embedded in paraffin according to routine protocols. Sections 4- $\mu \mathrm{m}$ thick were deparaffinized and hydrated using graded ethanols following routine protocols. For antigen retrieval, sections for Shh and Ptc immunostaining were microwave treated for 20 minutes in $10 \mathrm{~mm}$ citrate buffer at $700 \mathrm{~W}$. Sections for CDX2 immunohistochemistry were pretreated for 20 minutes in Target Retrieval Solution ( $\mathrm{pH} \mathrm{6.1;} \mathrm{DAKO,}$ Hamburg Germany). The sections were incubated overnight with primary goat anti-Shh and anti-Ptc antibodies (Shh [N19] 1:50; Ptc [C20] 1:10; Santa Cruz Biotechnology, Heidelberg, Germany) and mouse anti-CDX2 (1:100; DCS, Hamburg, Germany). After rinsing in Tris-buffer (0.5 M Tris, $\mathrm{pH}$ 7.4) detection was carried out with biotinylated secondary rabbit antigoat or rabbit antimouse antibodies diluted 1:50 (DAKO, Glostrup, Denmark) for 30 minutes at room temperature. The sections were washed as above in Trisbuffer and then incubated with streptavidin-biotinalkaline-phosphatase $(10 \mu l$ each solution $A+B$ (Sigma, Deisenhofen, Germany) in $10 \mathrm{ml}$ Tris-buffer). Immunohistochemical staining was visualized with Fast Red (2 mg Naphtol-As-Mx-phosphate, $10 \mu \mathrm{l} 1 \mathrm{M}$ levamisol, and $10 \mathrm{mg}$ Fast-Red (Sigma) in $0.2 \mathrm{ml}$ N,N-dimethylformamide, (Merck, Darmstadt, Germany) and $9.8 \mathrm{ml} \mathrm{0.1} \mathrm{M}$ Tris- $\mathrm{HCl}$ buffer at $\mathrm{pH}$ 8.6). The sections were rinsed in $\mathrm{dd} \mathrm{H}_{2} \mathrm{O}$ and counterstained with Mayer's hemalaun (Merck). Negative controls without primary antibody were run for each sample.
To detect Shh in gastric cancer cell lines, cells were spun to slides and fixed with acetone. Shh expression was visualized using anti-Shh antibodies and the respective secondary antibody in dilutions mentioned above. Again, omitting the primary antibody served as negative control.

\section{Cell Lines}

Three gastric cancer cell lines were tested for Shh transcription and expression. The gastric cancer cell line 23132 was derived from human gastric adenocarcinoma (Vollmers et al, 1993). HGT-1 (kindly provided by Dr. R. Negrini, Brescia, Italy) was chosen because of its features of gastric parietal cells (Carmosino et al, 2000; Laboisse et al, 1982). Finally, gastric cancer cell line AGS represents one of the standard gastric cancer cell lines widely used in different experimental settings (Barranco et al, 1983). All cells were grown in DMEM-Medium (Invitrogen, Karlsruhe, Germany) plus $10 \%$ heat-inactivated FCS (Invitrogen) at an atmosphere containing $5 \% \mathrm{CO}_{2}$.

To examine the potential role of $\mathrm{pH}$ on Shh transcription cell culture medium in the environment, $\mathrm{pH}$ value was adjusted to 5.0 to 7.5 using $3 \mathrm{M} \mathrm{HCl}$ at the beginning of cultivation period. Three days later, cells were detached using trypsin (Invitrogen); samples were subdivided for RNA isolation and Western blot and centrifuged 10 minutes at $300 \times g$. Cell pellets were lysed in RLT-buffer (Qiagen, Hilden, Germany) for RNA preparation and in M-PER lysis buffer (Perbio Science, Bonn, Germany) for Western blot experiments, respectively. Cell culture experiments were performed in triplicate.

\section{Western Blot}

For Western blot analysis, whole cell lysates of gastric cancer cell lines 23132, HGT-1, and AGS (5 $\mu \mathrm{g}$ total protein per lane) were subjected to sodium dodecyl sulfate-polyacrylamide gel electrophoresis on $12 \%$ polyacrylamide gels (Laemmli, 1970). The separated proteins were transferred to a nitrocellulose membrane and blocked for 4 hours in $0.1 \mathrm{M}$ Tris-buffer $(\mathrm{pH}$ 7.5) containing 4\% (weight/volume) dried skimmed milk and $0.1 \%$ Tween 20 at room temperature. Membranes were incubated with anti-Shh primary antibody (see Immunohistochemistry section; diluted 1:100) overnight. For detection of bound Shh antibodies, a horseradish peroxidase-conjugated rabbit antigoat antibody (diluted 1:7500; DAKO) was used. Finally, Western blots were developed with the SuperSignal substrate kit (Pierce, Bonn, Germany) according to the manufacturer's protocol.

\section{RNA Isolation and RT}

Total cellular RNA was extracted from the cell lysates by RNeasy kit in combination with DNAse treatment (Qiagen) as described in the manual. The RNA was eluted in $30 \mu$ l of RNAse-free water. First-strand cDNA was synthesized using Superscript II RNAse $\mathrm{H}$-Reverse Transcriptase (Life Technologies, 
Karlsruhe, Germany). $4 \mu$ of RNA-eluate were added to $1 \mu \mathrm{g}$ of dT15 primers (TIB-Biomol, Berlin, Germany) and $1 \mu \mathrm{M}$ random hexamers (Promega, Heidelberg, Germany). After annealing for 10 minutes at $70^{\circ} \mathrm{C}$ and immediate cooling on ice $1 \times$ first strand buffer (Life Technologies, Karlsruhe, Germany), 10 mm DTT (Life Technologies), $0.5 \mu$ l enzyme (100 units), and $0.5 \mathrm{~mm}$ deoxynucleotide triphosphate (Carl Roth, Karlsruhe, Germany) were added to form a total reaction volume of $10 \mu \mathrm{l}$. The reaction was allowed to proceed for 50 minutes at $37^{\circ} \mathrm{C}$, followed by 15 minutes at $70^{\circ} \mathrm{C}$ to inactivate the enzyme. After cDNA synthesis, distilled water was added to achieve a final volume of $100 \mu \mathrm{l}$ in each sample.

\section{RT-PCR}

Shh and GAPDH intron-overlapping primers were designed by use of the Primer Express software (Version 1.6, Applied Biosystems, Darmstadt, Germany). The sequences of primers and probes were as follows: $\mathrm{SHH}$ (NCBI reference sequence no. NM_000193, amplicon 74 bp): forward primer (exon 3): 5'- GGAAGCAGCCTCCCGATT -3'; reverse primer (exon 2): 3'- CGAGTCCAAGGCACATATCCA -5'. GAPDH (NCBI reference sequence no. NM_002046, amplicon 226 bp): forward primer (exon 4): 5'-GAAGGTGAAGGTCGGAGTC- 3'; reverse primer (exon 2): 3'-GAAGATGGTGATGGGATाTC-5'.

For qualitative PCR reaction, mixtures $(25 \mu \mathrm{l})$ were prepared containing $5 \mu \mathrm{l}$ of cDNA, forward and reverse primer (MWG-Biotech, Ebersberg, Germany) $500 \mathrm{~nm}$ each, $200 \mu \mathrm{m}$ dNTPs, $1 \times$ reaction buffer, $1 \mathrm{~mm}$ $\mathrm{MgCl} 2$ and $0.07 \mu \mathrm{l}$ (0.35 units) of Silverstar Taq Polymerase (Eurogentec, Cologne, Germany). After an initial denaturation step of 4 minutes at $95^{\circ} \mathrm{C}, \mathrm{PCR}$ assays were carried out with 35 cycles of denaturation at $95^{\circ} \mathrm{C}$ for 20 seconds, annealing at $60^{\circ} \mathrm{C}$ for 20 seconds, and extension at $72^{\circ} \mathrm{C}$ for 20 seconds. The samples were subjected to $2 \%$ agarose gel electrophoresis, and product was visualized using ethidium bromide (Sigma-Aldrich, Munich, Germany) and UV light source.

For real-time quantitative $\mathrm{PCR}$ reaction, mixture consisted of $5 \mu \mathrm{l} \mathrm{cDNA,} 12.5 \mu \mathrm{l}$ SYBRGreen PCR Master Mix (Applied Biosystems, Martinsried, Germany) and forward/reverse primers (MWG-Biotech, Ebersberg, Germany) in the following concentrations: $400 \mathrm{~nm}$ each for Shh and $800 \mathrm{~nm}$ each for GAPDH to a final volume of $25 \mu \mathrm{l}$. After denaturation and activation of included hot-start enzyme for 10 minutes at $95^{\circ} \mathrm{C}$, PCR assays were carried out with 40 cycles of denaturation at $95^{\circ} \mathrm{C}$ for 15 seconds, annealing and extension at $60^{\circ} \mathrm{C}$ for 1 minute. Each PCR assay was repeated 2 times for each cDNA sample. To monitor amplification of possible contamination, DNA samples of distilled water served as negative control.

Fluorometric PCR was performed with the ABI Prism 7700 Sequence Detection System (Perkin Elmer Applied Biosystems, Foster City, California). After target amplification SYBRGreen specifically binds to double-strand DNA, which leads to an increase in detectable fluorescence signal. The amount of product detectable through fluorescence signal at any given cycle within the exponential phase of PCR is proportional to the initial number of template copies. The number of PCR cycles needed to detect the amplicon is therefore a direct measure of template concentration. Threshold cycle (CT) is set when emission intensity of measurable fluorescence calibrated to starting level becomes equal to 10 standard deviations of the baseline.

Absolute quantitation was achieved through generation of standard curves using serial dilutions of known concentrations of the different cDNAs. The RT-PCR results were expressed as the ratio of molecules of target gene (Shh) per 1000 molecules of housekeeping gene (GAPDH). To monitor amplification of genomic DNA due to pseudogenes, RNA aliquots without $\mathrm{RT}$ were always amplified as negative controls.

After each PCR run, melting curve analysis was performed as follows. After denaturation at $95^{\circ} \mathrm{C}$ for 20 seconds, a temperature ramp from $60^{\circ} \mathrm{C}$ to $95^{\circ} \mathrm{C}$ in 20 minutes was run with simultaneous acquisition of fluorescence signal. At the melting point of doublestrand PCR products, an accelerated decline of fluorescence can be recognized. Using negative first deviation plots, each sample was checked for primer dimers and unspecific products due to mispriming.

Furthermore, agarose gel electrophoresis of selected samples out of each PCR run was performed to check for unspecific amplification products.

\section{Acknowledgements}

We thank Christa Winkelmann and Andrea Kosel for excellent technical assistance and Gerald Niedobitek for critically reading the manuscript.

\section{References}

Almeida R, Silva E, Santos-Silva DG, Wang J, De Bolos C, and David L (2003). Expression of intestine-specific transcription factors, CDX1 and CDX2, in intestinal metaplasia and gastric carcinomas. J Pathol 199:36-40.

Barranco SC, Townsend CM, Jr., Casartelli C, Macik BG, Burger NL, Boerwinkle WR, and Gourley WK (1983). Establishment and characterization of an in vitro model system for human adenocarcinoma of the stomach. Cancer Res 43: 1703-1709.

Biasco G, Paganelli GM, Brillanti S, Lalli AA, Brandi G, Terranova A, Miglioli M, and Barbara L (1989). Cell renewal and cancer risk of the stomach: Analysis of cell proliferation kinetics in atrophic gastritis. Acta Gastroenterol Belg 52:361366.

Canfield V, West AB, Goldenring JR, and Levenson R (1996). Genetic ablation of parietal cells in transgenic mice: A new model for analyzing cell lineage relationships in the gastric mucosa. Proc Natl Acad Sci USA 93:2431-2435.

Carmosino M, Procino G, Casavola V, Svelto M, and Valenti $G$ (2000). The cultured human gastric cells HGT-1 express the principal transporters involved in acid secretion. Pflugers Arch 440:871-880. 
Claeys D, Faller G, Appelmelk BJ, Negrini R, and Kirchner T (1998). The gastric $\mathrm{H}+, \mathrm{K}+-$ ATPase is a major autoantigen in chronic Helicobacter pylori gastritis with body mucosa atrophy. Gastroenterol 115:340-347.

Correa P (1988). A human model of gastric carcinogenesis. Cancer Res 48:3554-3560.

Eda A, Osawa H, Satoh K, Yanaka I, Kihira K, Ishino Y, Mutoh $\mathrm{H}$, and Sugano K (2003). Aberrant expression of CDX2 in Barrett's epithelium and inflammatory esophageal mucosa. J Gastroenterol 38:14-22.

Eurohepygast S (2002). Risk factors for atrophic chronic gastritis in a European population: Results of the Eurohepygast study. Gut 50:779-785.

Judd LM, Gleeson PA, Toh BH, and van Driel IR (1999). Autoimmune gastritis results in disruption of gastric epithelial cell development. Am J Physiol 277:G209-G218.

Kakei N, Ichinose M, Tatematsu M, Shimizu M, Oka M, Yahagi N, Matsushima M, Kurokawa K, Yonezawa S, Furihata C, and et al (1995). Effects of long-term omeprazole treatment on adult rat gastric mucosa: Enhancement of the epithelial cell proliferation and suppression of its differentiation. Biochem Biophys Res Commun 214:861-868.

Kakei N, Ichinose M, Tsukada S, Tatematsu M, Tezuka N, Furihata C, Yahagi N, Matsushima M, Miki K, Kurokawa K, and et al (1993). Effects of omeprazole on gastric mucosal growth and differentiation in developing rat. Biochem Biophys Res Commun 197:310-318.

Kuipers EJ, Lundell L, Klinkenberg-Knol EC, Havu N, Festen HP, Liedman B, Lamers CB, Jansen JB, Dalenback J, Snel P, et al (1996). Atrophic gastritis and Helicobacter pylori infection in patients with reflux esophagitis treated with omeprazole or fundoplication. N Engl J Med 334:1018-1022.

Laboisse CL, Augeron C, Couturier-Turpin MH, Gespach C, Cheret AM, and Potet F (1982). Characterization of a newly established human gastric cancer cell line HGT-1 bearing histamine H2-receptors. Cancer Res 42:1541-1548.

Laemmli UK (1970). Cleavage of structural proteins during the assembly of the head of bacteriophage T4. Nature 227:680-685.

Lamberts R, Brunner G, and Solcia E (2001). Effects of very long (up to 10 years) proton pump blockade on human gastric mucosa. Digestion 64:205-213.

Li Q, Karam SM, and Gordon JI (1996). Diphtheria toxinmediated ablation of parietal cells in the stomach of transgenic mice. J Biol Chem 271:3671-3676.

Marchetti M, Caliot E, and Pringault E (2003). Chronic acid exposure leads to activation of the cdx2 intestinal homeobox gene in a long-term culture of mouse esophageal keratinocytes. J Cell Sci 116:1429-1436.

Miwa $\mathrm{H}$, Endo K, Wada R, Hirai S, Hirose M, Misawa $\mathrm{H}$, Nagahara A, Ohta K, Watanabe S, and Sato N (1997). Cellular proliferation and differentiation in rat atrophic gastric mucosa induced by N'-methyl-N'-nitro-N-nitrosoguanidine. J Clin Gastroenterol 25:S116-S121.

Mo R, Kim JH, Zhang J, Chiang C, Hui CC, and Kim PC (2001). Anorectal malformations caused by defects in sonic hedgehog signaling. Am J Pathol 159:765-774.

Moss SF, Valle J, Abdalla AM, Wang S, Siurala M, and Sipponen P (1999). Gastric cellular turnover and the devel- opment of atrophy after 31 years of follow-up: A case-control study. Am J Gastroenterol 94:2109-2114.

Mullor JL, Sanchez P, and Altaba AR (2002). Pathways and consequences: Hedgehog signaling in human disease. Trends Cell Biol 12:562-569.

Neu B, Randlkofer P, Neuhofer M, Voland P, Mayerhofer A, Gerhard M, Schepp W, and Prinz C (2002). Helicobacter pylori induces apoptosis of rat gastric parietal cells. Am J Physiol Gastrointest Liver Physiol 283:G309-G318.

Ramalho-Santos M, Melton DA, and McMahon AP (2000). Hedgehog signals regulate multiple aspects of gastrointestinal development. Development 127:2763-2772.

Roberts DJ, Johnson RL, Burke AC, Nelson CE, Morgan BA, and Tabin $C$ (1995). Sonic hedgehog is an endodermal signal inducing Bmp-4 and Hox genes during induction and regionalization of the chick hindgut. Development 121:3163-3174.

Scarff KL, Judd LM, Toh BH, Gleeson PA, and Van Driel IR (1999). Gastric $H(+), K(+)$-adenosine triphosphatase beta subunit is required for normal function, development, and membrane structure of mouse parietal cells. Gastroenterol 117:605-618.

Seno H, Oshima M, Taniguchi MA, Usami K, Ishikawa TO, Chiba T, and Taketo MM (2002). CDX2 expression in the stomach with intestinal metaplasia and intestinal-type cancer: Prognostic implications. Int J Oncol 21:769-774.

Silberg DG and Kaestner KH (2001). Morphogenesis and maintenance of the gastric epithelium: A role for sonic hedgehog? Gastroenterol 121:485-487.

Silberg DG, Sullivan J, Kang E, Swain GP, Moffett J, Sund NJ, Sacke SD, and Kaestner KH (2002). Cdx2 ectopic expression induces gastric intestinal metaplasia in transgenic mice. Gastroenterol 122:689-696.

Spicer Z, Miller ML, Andringa A, Riddle TM, Duffy JJ, Doetschman T, and Shull GE (2000). Stomachs of mice lacking the gastric $\mathrm{H}$, K-ATPase alpha -subunit have achlorhydria, abnormal parietal cells, and ciliated metaplasia. J Biol Chem 275:21555-21565.

Steininger $\mathrm{H}$, Faller $\mathrm{G}$, Dewald $\mathrm{E}$, Brabletz $\mathrm{T}$, Jung $\mathrm{A}$, and Kirchner T (1998). Apoptosis in chronic gastritis and its correlation with antigastric autoantibodies. Virchows Arch 433:13-18.

Tucci A, Poli L, Tosetti C, Biasco G, Grigioni W, Varoli O, Mazzoni C, Paparo GF, Stanghellini V, and Caletti G (1998). Reversal of fundic atrophy after eradication of Helicobacter pylori. Am J Gastroenterol 93:1425-1431.

Uemura N, Okamoto S, Yamamoto S, Matsumura N, Yamaguchi S, Yamakido M, Taniyama K, Sasaki N, and Schlemper RJ (2001). Helicobacter pylori infection and the development of gastric cancer. N Engl J Med 345:784-789.

van den Brink GR, Hardwick JC, Nielsen C, Xu C, Ten Kate FJ, Glickman J, van Deventer SJ, Roberts DJ, and Peppelenbosch MP (2002). Sonic hedgehog expression correlates with fundic gland differentiation in the adult gastrointestinal tract. Gut 51:628-633.

van den Brink GR, Hardwick JC, Tytgat GN, Brink MA, Ten Kate FJ, Van Deventer SJ, and Peppelenbosch MP (2001). Sonic hedgehog regulates gastric gland morphogenesis in man and mouse. Gastroenterol 121:317-328. 
Villavicencio $\mathrm{EH}$, Walterhouse DO, and lannaccone PM (2000). The sonic hedgehog-patched-gli pathway in human development and disease. Am J Hum Genet 67:1047-1054.

Vollmers HP, Stulle K, Dammrich J, Pfaff M, Papadopoulos T, Betz C, Saal K, and Muller-Hermelink HK (1993). Characterization of four new gastric cancer cell lines. Virchows Arch B Cell Pathol Incl Mol Pathol 63:335-343.
Vorobjova T, Maaroos HI, Sipponen P, Villako K, and Uibo R (2001). Apoptosis in different compartments of antrum and corpus mucosa in chronic Helicobacter pylori gastritis. An 18-year follow-up study. Scand J Gastroenterol 36:136-143. 